\title{
Monoclonal Antibody Production Shared Resource
}

National Cancer Institute

\section{Source}

National Cancer Institute. Monoclonal Antibody Production Shared Resource. NCI

Thesaurus. Code C39462.

The Monoclonal Antibody Production Shared Resource is responsible for monoclonal antibody generation and production, provides other antibody-related products and services to support basic research and clinical projects at Cancer Center, and conducts research on the development of related novel immunological techniques. 